\title{
Derechos colectivos y propiedad colectiva de territorios de los pueblos indígenas de la provincia de Sucumbíos,
}

Ecuador

\section{TXURI OLLO GORRITI}

> Departamento de Trabajo Social, Universidad Pública de Navarra, Pamplona - Iruña, España. txuri.ollo@unavarra.es

Universidad de Valparaíso

Facultad de Arquitectura

Revista Márgenes

Espacio Arte Sociedad

Derechos colectivos y propiedad colectiva de territorios de los

pueblos indígenas de la provincia de Sucumbíos (Ecuador)

Diciembre 2015 Vol. $12 \mathrm{~N}^{\circ} 17$

Páginas 34 a 42

ISSN elec. 0719-4463

ISSN imp. 0718-4034

Recepción: septiembre 2015

Aceptación: noviembre 2015

\section{RESUMEN}

En las últimas décadas las reivindicaciones de sus derechos, a los pueblos indígenas les han llevado a la necesidad de revisar los fundamentos teóricos básicos de los derechos humanos, de esos derechos llamados universales pero que en la realidad son violados continuamente, afrontando situaciones de vulnerabilidad y desigualdad. En esta creciente expansión de la colonización y del sistema capitalista, ven reducir su libertad de movimiento, por lo que urge la necesidad de emprender nuevas formas de resistencia ante las graves amenazas de mantenimiento y utilización de sus tierras, territorios y recursos naturales. Con la vindicación del reconocimiento de los derechos colectivos, tanto económicos como culturales, hoy estos pueblos indígenas que han sido la materia prima de las políticas de modernización y desarrollo, se convierten en el motor de los cambios de paradigma social, criticando el mantenimiento de privilegios raciales, sexistas, clasistas y colonialistas, aportando parámetros y reflexiones para una auténtica descolonización tanto del pensamiento como de la práctica, llevando a cabo proyectos emancipadores.

PALABRAS CLAVE

colonialidad, derechos colectivos, descolonización

\section{Collective rights and collective land property of the indigenous people in the Province of Sucumbíos, Ecuador \\ ABSTRACT}

In recent decades, the struggle from positions of vulnerability and inequality to defend their rights has required indigenous peoples to revise the theoretical bases underlying the concept of human rights, rights which, though termed universal, are in reality constantly violated. In the ongoing expansion of colonization and the capitalist system their freedom of movement has been reduced, leading them to undertake new forms of resistance in the face of severe threats to the possession and use of their land, territories and natural resources. In their fight for the recognition of their collective rights, both economic and cultural, these peoples, who have been, till now, the window-dressing of policies of modernization and development, have today become the driving force of changes in the social paradigm, by their critique of ongoing race, gender, class and colonial privileges, by contributing context and analysis for an authentic decolonization both of thought and of praxis and by carrying out emancipatory projects.

KEYWORDS

colonialism, collective rights, decolonization

\section{INTRODUCCIÓN}

Los derechos llamados universales, que no han sido ni tan universales ni tan humanos dejan ver sus deficiencias en la realidad de los pueblos originarios amazónicos, quienes siguen enfrentando continuamente situaciones de vulnerabilidad y desigualdad. La expansión capitalista reduce no sólo la libertad de movimiento indígena, sino que pone en riesgo el medio ambiente ante la acción destructiva de empresas nacionales y transnacionales con la venia de los gobiernos de turno que supuestamente deberían proteger a los habitantes de las áreas bajo su jurisdicción. El reclamo insistente del reconocimiento de los derechos colectivos, tanto culturales como de la tenencia de tierras y/o territorios, ha llevado a la inclusión de ellos en las diferentes constituciones, leyes y tratados internacionales, pero no ha ido a la par del respeto pleno por parte del Estado al ejercicio de estos derechos. 
Estos pueblos indígenas hoy, pueden ser o son el motor de los cambios de paradigma, aportando parámetros y enriqueciendo el pensamiento y la actuación de políticas nacionales e internacionales, sobre todo de países que se resisten a perder privilegios. Los sistemas de propiedad comunitaria reconocen el valor intrínseco de la biodiversidad y buscan la utilización de los recursos basándose en principios de justicia y sostenibilidad, compaginando derechos y responsabilidades en la utilización y conservación del medio.

Este artículo muestra la situación de una joven provincia de la Amazonía Ecuatoriana, que nace a raíz de la explotación petrolera en la segunda mitad del siglo XX. Desde el año 2006 integrantes del equipo de investigación LERA antropólogo/as sin fronteras de la Universidad Pública de Navarra UPNA, hemos participado en un proyecto de Cooperación al Desarrollo Cultural, junto al equipo que trabaja en el Departamento de Nacionalidades y Pueblo Afroecuatoriano del Gobierno Provincial de Sucumbíos, compuesto por las nacionalidades Kichwa, Shuar, A`i i, Sionabai y Siecopai.

Entre otros trabajos se ha colaborado en la capacitación en técnicas de investigación antropológica al equipo citado para que ellos y ellas llevaran a cabo la recopilación de conocimientos para la elaboración de un libro que posteriormente se editó con el nombre de Saberes Ancestrales de Sucumbíos ${ }^{1}$. De la relación mantenida desde entonces con las poblaciones indígenas de esta provincia y las reflexiones conjuntas nace este documento que aquí se presenta. Es una mirada a los esfuerzos locales de estos pueblos originarios por mantener y desarrollar su cultura.

El ensayo trata de plantear, visibilizar y transformar las relaciones que diferencialmente posicionan grupos, prácticas y pensamientos que todavía son raciales, sexistas, clasistas y colonialistas. Su objetivo es el de contribuir al debate y a la reflexión de la necesidad de descolonizar el pensamiento y la práctica. Intenta visualizar la profundidad y la aceleración de los cambios a los que se ven sometidos los pueblos originarios. Después presenta una referencia conceptual sobre los llamados territorios indígenas, así como de la colonialidad del poder, esto es, la utilización de la idea de "raza" como fundamento del patrón universal de clasificación social y de dominación social. Para cerrar analiza los movimientos emancipatorios recientes en este entorno ecuatoriano.

El proceso de empoderamiento o de "re-empoderamiento" 2 de las comunidades indígenas, se enfrenta a las grandes resistencias de un sistema cimentado en las desigualdades y en la apropiación de bienes, así como a la incrementación de las dependencias, sin reconocer las propias del sistema con las poblaciones a las que se intenta seguir sometiendo, para sacar un beneficio óptimo que va a las arcas de personas y grupos particulares minoritarios que acumulan y ejercen poder económico y político.

Las poblaciones indígenas hoy quieren ser agentes activos en la defensa de sus derechos culturales y territoriales, quieren ser incluidos en las tomas de decisiones que les atañen y tomar las riendas de su destino.

\section{TERRITORIOS INDÍGENAS}

El derecho y la jurisdicción sobre el subsuelo es todavía una situación controvertida, a pesar de los avances en la validadión del Derecho Internacional en cuanto a los llamados Territorios Indígenas ${ }^{3}$. Un proceso relevante es el caso de Sarayacu ${ }^{4}$, comunidad kichwa de la Amazonía ecuatoriana que en junio de 2012 consiguió des-

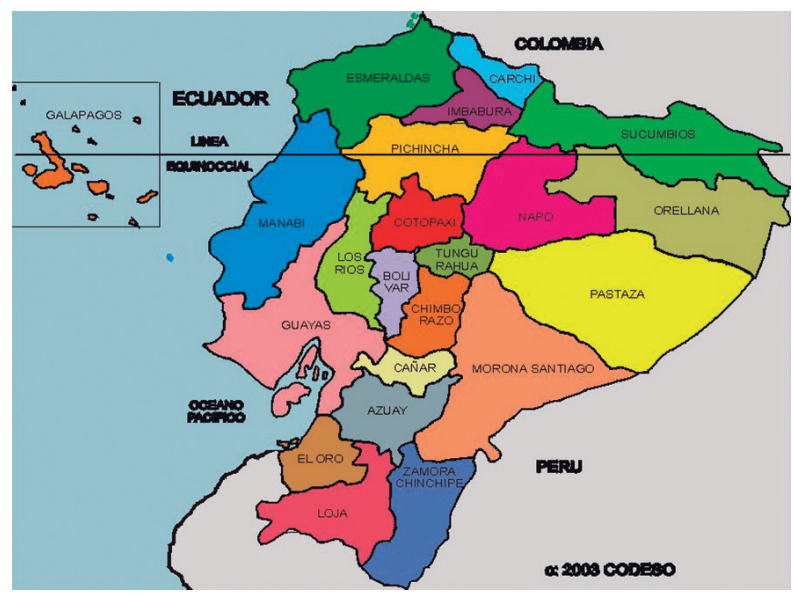


pués de varios años de movilizaciones, que la Corte Interamericana de Derechos Humanos ${ }^{5}$ declarara, que el Estado del Ecuador era responsable de la violación de los derechos de propiedad comunal indígena, por haber permitido que una empresa petrolera privada realizara actividades de exploración y explotación en su territorio, desde finales de los años 90 , sin haberle consultado previamente y por tanto sin su consentimiento.

Las incursiones de las compañías petroleras, en la actualidad siguen siendo el principal problema que enfrentan las comunidades amazónicas. Las explotaciones del crudo vienen acompañados por el acelerado proceso de colonización con la expansión de la frontera agrícola. Al ampararse en el derecho consuetudinario hay quien opina que la ley puede referirse a aquellos recursos naturales que han sido utilizados tradicionalmente pero que lo que hay debajo del subsuelo debe ser gestionado por el Estado. Por otro lado determinar los usos tradicionales es controvertido ya que hay quien puede entender que el uso tradicional sería por ejemplo en el caso de la madera utilizar para la construcción de viviendas, piraguas u otros materiales de uso cotidiano o que debería ampliarse a las necesidades económicas de subsistencia y por tanto se podría comercializar sólo y exclusivamente por los habitantes que ocupen el territorio considerado en cada caso.

No cabría este debate si a la forma comunal de la propiedad colectiva le correspondieran los mismos derechos sobre los recursos naturales que a cualquier otra propiedad privada. El carácter colectivo de la propiedad de los pueblos indígenas sobre las tierras y los recursos naturales, lo diferencia de los sistemas liberales de propiedad individual predominantes. La existencia de una tradición comunitaria sobre la forma comunal de la propiedad de la tierra, en el sentido de que la pertenencia de ésta no se centra en un individuo sino en el grupo y su comunidad está fuertemente arraigada. El uso del término "propiedad comunal indígena" refuerza el reconocimiento de derechos colectivos recogido en el Convenio 169 de la OIT Organización Internacional del Trabajo ${ }^{6}$.

Esta agencia especializada de las Naciones Unidas señala en su página web inicial la necesidad de crear medios de vida sostenibles y salvar el ecosistema ${ }^{7}$. Esto nos lleva a visibilizar el punto de partida de esta agencia, que presupone que los medios de vida ya no son sostenibles y de que hay que crearlos, mientras no se subraya la necesidad de salvaguardar esos medios de vida sostenibles existentes y que están en grave riesgo de desaparecer. Muestra lo que se ha hecho con la naturaleza y la humanidad. Primero separar al ser humano de la naturaleza para culturizarlo y devolverlo después a la misma naturaleza una vez que ya se ha culturizado de una manera determinada. Pero las luchas emancipadoras de los pueblos originarios aumentan ante los tratados internacionales y se enfrentan a las políticas impositivas.

Por otro lado, si nos fijamos en los derechos culturales, las explotaciones petroleras, así como las madereras llevan consigo, la construcción de carreteras y centros industriales que conllevan cambios culturales significativos allá donde incursionan. Numerosas organizaciones indígenas han exigido a sus Estados el cumplimiento -en virtud tanto del derecho internacional consuetudinario, como del derecho internacional convencional- la necesidad de reconocer, respetar, salvaguardar y hacer efectivos los derechos de los pueblos indígenas sobre sus tierras, territorios y recursos naturales, para preservar su identidad cultural, pero la realidad dista de este cumplimiento.
El territorio es un espacio con significado multidimensional, vinculado a su autoidentificación e historia colectiva, donde se crean y recrean prácticas de ejercicio de autoridad, prácticas económicas, ecológicas, espirituales y culturales. Para los pueblos originarios el territorio es el requisito fundamental de su continuidad cultural, y requisito indispensable para garantizar la autodeterminación frente a los procesos de cambio.

El movimiento emancipatorio y descolonizante de los pueblos originarios pasa por la obtención de los derechos fundamentales para el desarrollo pleno de su cultura, por defenderse de la depredación de sus territorios por transnacionales u oligarquías locales, por liberarse de la dominación política, económica y cultural y sacudirse del yugo del sometimiento manteniendo su identidad diferenciada, son los puntos nodales del proceso de liberación e independencia no concluidos.

\section{EN BUSCA DE LOS DERECHOS PERDIDOS}

Las diferentes nacionalidades de la provincia de Sucumbíos se enfrentan a diversas dificultades para recuperar los derechos perdidos. La discontinuidad territorial o el carácter binacional o biprovincial al que los hechos históricos recientes o no tan recientes han llevado a los diferentes grupos, debilitan las posibilidades de negociar la delimitación, legalización, titulación y posterior implementación de los territorios étnicos. Se limita así la gestión colectiva de los territorios rompiendo las formas de ocupación y uso de los diferentes hábitats que han tenido las poblaciones amazónicas originarias, legalizando el despojo territorial.

Los Siekopai al igual que otras nacionalidades, han visto reducir sus territorios ancestrales a la par que su población, han visto peligrar su cultura a la par que se sacrifica el medio ambiente así como los recursos que habían posibilitado el desarrollo de su cultura. Este pueblo transfronterizo ubicado entre Perú y Ecuador ha sufrido la división territorial y comunal en el proceso de colonización que no cesa a lo largo de los tiempos.

A comienzos del siglo XX se vieron forzados a la sedentarización a consecuencia de la expansión de la economía extractivo-mercantil, cuya expresión más nítida fue el boom del caucho, seguido por la actividad forestal (palo de rosa, entre otros) y el petróleo (en el lado ecuatoriano). Se inició así un largo período de subordinación y explotación bajo el sistema de dominio extractivista que se impuso en la región.

A partir de 1970 fueron afectados por la actividad petrolera de la compañía Texaco, y desde 1985 por la Occidental Exploration and Production Company (más conocida como OXY), con una fuerte presión sobre su territorio y sus recursos: destrucción del bosque, contaminación del agua y aire, y por tanto disminución de animales de caza y pesca.

Las áreas que se han ido legalizando corresponden a una parte muy reducida de sus territorios históricos, sin continuidad territorial en este caso así como en la mayoría de las nacionalidades, mientras la población colona incursiona continuamente en estos territorios, sin que se tomen medidas administrativas al respecto.

Santiago Alba cuando se pregunta sobre el valor del ser humano señala que es el tiempo que hemos trabajado en él [...] No cuidamos los cuerpos humanos porque tengan valor sino que, al contrario, adquieren valor en la medida en que los cuidamos y los tocamos y los miramos; en la medida, en definitiva, en que los trabajamos (Alba, 
2013). Extrapolando esta afirmación a la naturaleza, su valor estaría directamente relacionado con el tiempo que le dedicamos a su cuidado, el tiempo que dedicamos a mirarlo, a observarlo, a tocarlo, a quererlo, a trabajarlo. He ahí la diferencia en la relación de las personas con su medio. Los pueblos originarios de cualquier lugar del mundo hemos estado estrechamente ligados a la naturaleza, al territorio, a la tierra, a la flora, a la fauna, a los fenómenos meteorológicos, a la integralidad del cosmos y además queremos continuar con esa vinculación, no hay porqué justificar ese sentimiento, ese deseo, esa necesidad, ni con la tradición, ni con los ancestros. No se necesita justificar el deseo de libertad y el deseo de amar.

Los colonos y colonas tienen una visión diferente sobre la conservación de la naturaleza, tienen la idea de explotar cuanto más mejor. Compran y venden todo. La población indígena no hace eso, tenemos escrituras globales, vivimos en la naturaleza, la cuidamos, es todo para nosotros, nuestro supermercado, nuestro hospital, nuestro lugar de culto, nuestra escuela (Testimonio de Hugo Payaguaje, Ecuador, 2007).

Cada Nacionalidad tiene su propia organización que lucha por recuperar sus derechos. La OISE, Organización Indígena Siekopai del Ecuador es una de ellas. Al ser conscientes de los cambios que se estaban produciendo y ver en peligro su sobrevivencia física y cultural, así como la pérdida de la capacidad de decisión en torno a los intereses fundamentales en su vida surgió esta organización con el propósito de que toda la comunidad participara en esa toma de decisiones haciendo frente a los agentes externos que les venían imponiendo sus políticas económicas y culturales, limitando cada vez más sus territorios y pensamientos, llevándolos a una mayor dependencia en todas las facetas de su vida. A partir de su surgimiento en los años 90 fomenta iniciativas de participación comunal, promoviendo proyectos de desarrollo comunitario. Actualmente tiene un reconocimiento político que se ve amparado por su participación en la CONAIE (Confederación de Nacionalidades Indígenas del Ecuador) y CONFENIAE (Confederación de Nacionalidades Indígenas de la Amazonia Ecuatoriana).

El proceso constituyente celebrado entre noviembre de 2007 y agosto de 2008, atravesó resistencias y oposiciones a las demandas del movimiento indígena encabezado por la CONAIE. La constitución aprobada en septiembre de 2008 recoge un capítulo específico sobre Derechos de las Comunidades, Pueblos y Nacionalidades de Ecuador reconociendo los derechos colectivos en el uso, usufructo, administración y conservación de los recursos naturales renovables que se hallen en sus tierras; derecho a conservar y desarrollar sus propias formas de convivencia y organización social; derecho a mantener, proteger y desarrollar los conocimientos colectivos y los recursos genéticos (medicinas, plantas, animales, minerales y ecosistemas); quedando prohibida toda forma de apropiación de esos conocimientos, innovaciones y prácticas (Capítulo cuarto, Art. 57, incisos 6, 8, 12).

Así mismo en el inciso 7 se recoge el derecho a la consulta previa, libre e informada, sobre planes y programas de prospección, explotación y comercialización de recursos no renovables que se encuentren en sus tierras y que puedan afectarles ambiental o culturalmente; a participar en los beneficios que esos proyectos reporten, así como a recibir indemnizaciones por los perjuicios sociales, culturales y ambientales que les causen. No recoge el Derecho de las comunidades al Consentimiento libre, previo e informado. Pero

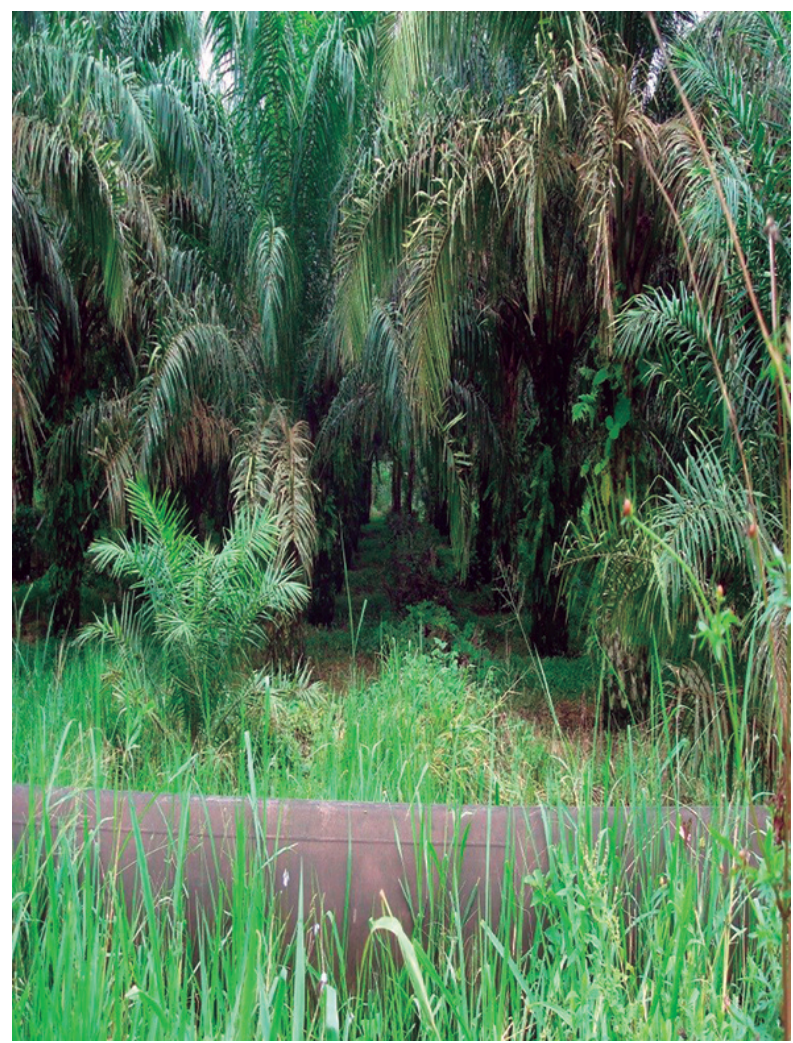

Figura 2. Plantaciones de Palma Africana y oleoducto transecuatoriano de Sucumbíos. Foto del autor. 
sí lo hace el antes mencionado Convenio 169 de la OIT. Ricardo Cerda, uno de los primeros pobladores kichwas de la provincia de Sucumbíos y organizador de las primeras comunidades señala:

Cuando entró Texaco, no había nada todavía, antes entraban libremente, por las fincas, por las comunas, nadie decía nada... hacian lo que querían, ellos venían con los militares y policías para mandar a la gente que hacía bulla, luego vino de que los que han tenido daños ya empezaron a decir ino! ustedes de cada planta tienen que pagar tanto... después de tanta pelea nosotros también aprendimos a exigir. Ahora tienen que negociar (Testimonio de Cerda, Ecuador, 2008).

Estas negociaciones no están ni han estado libres de conflictos, de engaños y de chantajes. Los incursionistas utilizan diversas tácticas que les permiten la entrada y estadía con la consiguiente explotación del medio. La falta de información fue y es una de las principales estrategias, pero el uso de información tergiversada, o el evitar la organización de la gente desarrollando procedimientos democráticos en las tomas de decisiones acompañan también a estos procesos colonialistas.

Dadas las exigencias y las protestas de la población, ha habido alguna mejora en las técnicas de prospección y explotación petrolera en los últimos años, siempre con un compromiso de cumplir el convenio de cooperación que las comunidades exigen por los daños y perjuicios que puedan ocasionar, y el plan de remediación e indemnización en caso de que haya desastres. Pero no siempre se cumplen los acuerdos firmados o los compromisos adquiridos, lo que lleva a estar en continua tensión, llegando a maltratos, heridos, detenciones, encarcelamientos e incluso muertos en numerosas ocasiones.

\section{LAS VÍAS DESCOLONIZANTES}

Diversos autores han analizado lo que han llamado la colonialidad, así como la colonialidad del poder y del saber, para centrarse en la necesidad de un proceso de descolonización tanto del pensamiento como de la práctica en los actuales movimientos sociales y políticos. Han hablado de la necesidad de deconstruir la hegemonía eurocéntrica o etnocéntrica que establece un sistema de clasificación social basada en una jerárquica racial, sexual, religiosa, lingüística, clasista, militar, medical, educativa, ecológica, pedagógica, y epistemológica en la formación y distribución de identidades sociales en lo que se ha llamado entramado de jerarquías de poder globales.

La colonialidad ${ }^{8}$ tal como la define Walter Mignolo está presente hoy en día en el mundo indígena amazónico. La modernidad neoliberal implica nuevas formas de colonización. El mercado, el consumo, la acumulación, son la nueva religión. Simultáneamente, el incremento de la producción y del PNB corre paralelo a la destrucción de la vida (los recursos naturales) y la transformación de la humanidad en recursos humanos, lo cual supone una nueva expresión del racismo (Mignolo, 2003:24).

La otredad construida en los procesos históricos es aplicada desde las instituciones y poblaciones nacionales hacia sus pueblos originarios, manteniendo el imaginario de: pueblos no civilizados o menos civilizados, primitivos y atrasados, partiendo de parámetros desarrollistas, justificando la dominación manifiesta en el control de la autoridad colectiva y de la subjetividad.
Los medios de comunicación han mostrado a los "otros", llenos de necesidades y problemas, desprovistos de opciones y libertades, pobres, ignorantes, vagos y tradicionalistas, mientras destacan en los demás la modernidad, la educación y la tecnología.

La difusión de la economía de mercado rompió en gran parte, los lazos comunitarios, implantando nuevas formas de intervención social. El sueño del desarrollo se convirtió en pesadilla, señala Arturo Escobar. En vez del reino de la abundancia prometido por teóricos y políticos de los años 50 el desarrollo de unos se construyó sobre la miseria y subdesarrollo de otros, sobre la explotación, opresión y violencia, despojándolos de sus recursos naturales. Los valores del progreso y del desarrollo llegaron acompañados de la imposición del malestar para las mayorías (Escobar, 2007).

Se siguen manteniendo los privilegios de unos a costa de las desigualdades y de la dominación, se continúa construyendo la idea de la superioridad en las formas de vivir, de ser, de estar, de pensar, inferiorizando, desvalorizando y deshumanizando al "otro" cuando éste ha sido desposeído de sus bienes de manera violenta.

Enrique Dussel delimita el concepto de dominación a la relación interestatal de "dependencia" mientras que el de "explotación" se determina para las relaciones personales/laborales (Dussel, 1992). Ambas se refieren a relaciones de poder tal como lo señala Aníbal Quijano. La explotación para este autor consiste en obtener de la acción de los demás un beneficio propio, sin coparticipación de los demás, sin retribución (Quijano, 1992). Caso que no es exactamente así aparentemente en la situación de la población indígena de Sucumbíos como en tantos otros, sino que la gente, las directivas, son manipuladas en sus decisiones, no dejando alternativas reales ni opciones viables. Esto provoca tiempos de silencio y de paz relativa, pero también tiempos de conflictos, siendo el objetivo de éstos el desmontaje de esas relaciones de dominio.

La teoría de la "colonialidad del poder" formulada originalmente por Quijano, a principios de los años noventa, y ampliada posteriormente por la red de intelectuales-activistas ligados a lo que se ha denominado Proyecto Modernidad / Colonialidad / Descolonialidad, es una de las propuestas epistémicas que nos aporta reflexiones para el análisis e interpretación de la realidad amazónica, erigiéndose la categoría de "colonialidad" (Quijano, 1992) como el nodo epistémico de la propuesta sobre la estructuración del poder en la modernidad.

Frente a esto Walter Mignolo propone el desarrollo del "paradigma otro", o sea, el desarrollo del pensamiento crítico que se articula en todos aquellos lugares en los cuales la expansión imperial/colonial le negó la posibilidad de razón, de pensamiento y de pensar en el futuro (Mignolo, 2003). Germina en las zonas de subalternidad colonial y/o imperial. En el pensamiento de quienes han vivido y aprendido en y desde el cuerpo la falta de respeto, el ninguneo, y la ignorancia de quienes hablan de derechos humanos. El autor manifiesta que:

Un "paradigma otro" surge del pensamiento que piensa la descolonización no como objeto (estudiando los movimientos de descolonización) sino como fuerza de pensamiento. No quiere estudiarse a sí mismo como objeto, sino "pensarse" a sí mismo en proyectos liberadores, emancipadores (Mignolo, 2003:31).

El “paradigma otro" está conectado a la experiencia del colonialismo y de la modernidad, a la colonialidad del poder. Por lo que 
es necesario visibilizar y deshacer los lugares de poder asignados a los distintos tipos de conocimiento. Visibilizar los otros lugares epistémicos, de historia, de memoria, de dolor, de lenguas y saberes diversos, que ya no son lugares de estudio, sino lugares de pensamiento, donde se genera pensamiento, donde se genera el bilenguajeo $^{9}$ y las epistemologías fronterizas (Mignolo, 2003). Un "paradigma otro" surge de la toma de conciencia y del análisis de la colonialidad del poder en el que se asentó, dominante y explotador, el proyecto de la modernidad.

El concepto de descolonización o la perspectiva de análisis decolonial, abarca una posición política atravesando el pensamiento y la acción individual y colectiva, actuando sobre el imaginario y sobre el cuerpo de quienes han sido subyugados y dominados por los diferentes mecanismos de poder.

Sabiendo que pensamos desde experiencias situadas y particulares, se hace necesario el reconocimiento de las experiencias políticas subalternas; visibilizar, plantear y transformar las relaciones, las prácticas y los pensamientos, descolonizando las mentes, yendo hacia una decolonialidad de las estructuras sociales.

La interculturalidad en este medio amazónico, pluricultural y pluriétnico es un proyecto político, entendido como un proceso continuo dirigido hacia la construcción de otros modos de poder, saber y ser, siendo capaces de incorporar conocimientos y experiencias múltiples, desactivando la creencia colonial que identifica diferencia con inferioridad (Bonet, 2009:18). La interculturalidad promueve mediante la ecología de saberes las epistemologías y prácticas de las diferentes poblaciones, que nos lleven a la complementariedad recíproca, desarrollando un pensamiento crítico. Tiene en cuenta las consecuencias del capitalismo y del colonialismo sobre quienes más han sufrido con ellos y busca democratizar la práctica transformando las relaciones de poder, para brindar a los diferentes pueblos las oportunidades que se merecen.

En este contexto surge la ecología de saberes como una nueva me todología de investigación y acción que privilegia la interactividad sobre la unilateralidad y propone un intercambio entre quienes poseen el conocimiento científico y aquellos sectores de la población que poseen otros tipos de conocimiento, como saberes sociales populares o artísticos, saberes subordinados y subalternos, explorando en la colonialidad del saber y del ser, del conocimiento y de la subjetividad. Decidir los conocimientos a transmitir y potenciar, los silencios que hay que visibilizar, descolonizar el saber en definitiva.

Para Boaventura de Sousa Santos la interculturalidad y el postcoIonialismo son los pilares fundamentales para el desarrollo de la ecología de saberes. La interculturalidad, para este sociólogo portugués, es el medio por el cual se traducen las culturas mutuamente (de Sousa, 2009). Sin traducción no es posible entender ni respetar las diferencias. No se trata de que haya conmensurabilidad absoluta, señala de Sousa. Sin embargo, esto no descarta espacios de negociación y respeto que permitan actuar políticamente juntos desde la diferencia de situaciones y proyectos políticos. La traducción intercultural permite conocerse porque las múltiples experiencias usan no sólo diferentes lenguas sino también diferentes categorías, universos simbólicos y aspiraciones para una vida mejor (de Sousa, 2009:32), por lo que la interculturalidad llevará a descentralizar los puntos de vista y a ampliar las visiones del mundo.

Descolonizar la posicionalidad privilegiada de unos grupos sobre otros, tal como señala Catherine Walsh, significa entre otras cosas, luchar por las siguientes demandas: pérdida de privilegio (social, político, económico, sexual, epistemológico, etc.) frente a los sujetos coloniales en busca de relaciones igualitarias, oponerse radicalmente a las agresiones imperiales/militares así como a la violencia policiaca, un antiracismo radical (Walsh, 2007) y por tanto interculturalizar la multiculturalidad, comprendiendo y respetando las diferencias.

\section{MOVILIZACIONES}

Esta provincia amazónica está inmersa en un proceso de colonización acelerada, colonización física del territorio y colonización cultural. Esto supone como todo proceso colonial la pérdida irreparable de la biodiversidad y de la diversidad cultural, con un sufrimiento incalculable para las poblaciones indígenas sumergidas en un cambio apresurado de su modo de vida, cuando no la desaparición de sus poblaciones por el deterioro de su medio ambiente. De la agricultura de subsistencia que acompañó durante siglos a la caza y la pesca, las poblaciones originarias se han visto obligadas a ser empleado/as de las grandes multinacionales petroleras, mineras, madereras, de explotaciones de palmicultura o cuando menos a dedicarse a la agricultura campesina o familiar.

Entiendo como agricultura campesina o familiar lo que se ha denominado como producción orientada por campesinos autónomos con una perspectiva holística de la actividad agrícola (incluyendo el respeto de la naturaleza, la producción orgánica y la salvaguardia del paisaje), la cual contrasta con la agricultura organizada de manera "industrial”, en función de la lógica del capital; en otras palabras, una agricultura orientada por el valor de uso versus una actividad agraria basada sobre el valor de cambio.

Los Foros Mundiales de Alternativas respecto del destino de las agriculturas y poblaciones del campo llevados a cabo en Beijing y La Paz (Bolivia) en 2010 y 2013 recogen las reivindicaciones formulando un llamamiento a los pueblos y Gobiernos, alertando sobre:

- El acaparamiento, concentración y extranjerización de tierras y territorios del campesinado y pueblos originarios;

- El papel de los monocultivos y de la agricultura extractivista, rentista y especulativa en el deterioro ambiental y crisis alimentaria. Ya que van acompañados por la introducción de transgénicos, aplicación de químicos altamente contaminantes y un paquete tecnológico concreto que crea mayores dependencias con introducción de organismos genéticamente modificados que alteran el ecosistema y crean dependencias;

- Las leyes, políticas, programas e iniciativas específicas para que avancen por la ruta de la soberanía alimentaria, la defensa de la naturaleza y la restauración de la convivencia social, pasando por la diversidad sociocultural de los pueblos y el reconocimiento de sus derechos (Hidalgo, Houtart, y Lizarraga, 2014).

Los movimientos emancipatorios y descolonizantes de estos pueblos originarios han dado sus frutos en el camino de la liberación de la dominación política, económica y cultural, han sacudido el yugo del sometimiento y mantienen las identidades diferenciadas, pero se enfrentan hoy al desarrollismo neocolonial. Desarrollismo y progresismo que defiende el extractivismo ${ }^{10}$.

Las movilizaciones del año 2015, así como otras anteriores en Ecuador, con todas sus dificultades muestran el camino hacia esa 


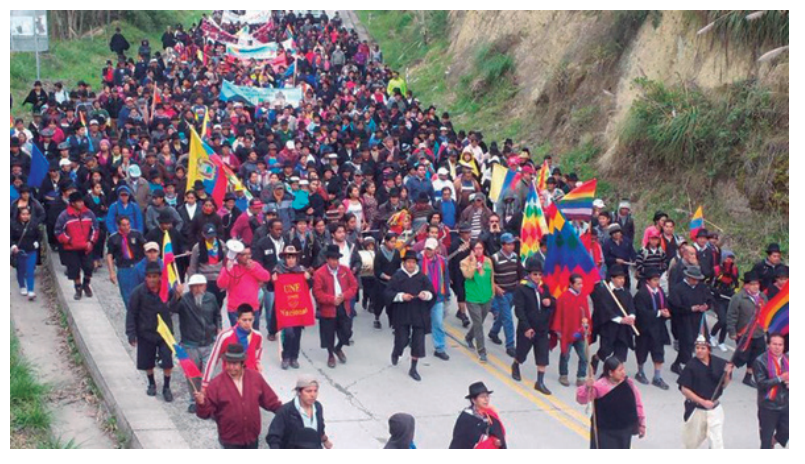

descolonización epistémica. La resistencia contra la dominación, contra la privatización de la selva, se plasma en diferentes vindicaciones y demandas históricas que señala la CONAIE ${ }^{11}$ a través de su vocero y presidente Jorge Herrera:

- La participación de las comunidades en la toma de decisiones sobre los asuntos que nos conciernen;

- Redistribución de los medios de producción garantizando tanto el sumak kawsay como la diversificación de la producción;

- Restablecimiento de la Educación Intercultural Bilingüe, que es parte de la preservación de la identidad cultural y que fue derogada por decreto ejecutivo en el 2009 por el gobierno de Rafael Correa. Escuelas que nacieron en 1945 a expensas de la administración, que fueron prohibidas en 1963 por ser centros de organización social y política, que lucharon por la reforma agraria y que se consolidaron en los 80 . Estas escuelas fueron cerradas para unificar en un solo currículo, en las llamadas "escuelas del Milenio" con profesorado monolingüe de supuestamente mayor nivel académico, acabando con la autonomía educativa. Por lo que el movimiento indígena exige el fortalecimiento de los modelos de educación comunitaria insertos en sus propias comunidades sin necesidad de largos desplazamientos, así como el desarrollo de un modelo pedagógico y difusión de conocimientos y saberes acorde con la realidad cultural y local;

- La reapertura de la Universidad indígena Amawatay Wasy cerrada en el 2013, por no estar dentro del modelo de educación colonizada, constituyendo una agresión violenta a los espacios logrados por el movimiento indígena (Tavares, 2015).

Exigieron también la suspensión de los tratados de Libre Comercio entre Ecuador y la Unión Europea, un contrato hecho en función de los intereses de la gran oligarquía terrateniente exportadora. Así como el fin de la política económica extractivista anclado en el desarrollismo, lo que llevará a un nuevo ciclo de endeudamiento.

Se mostraron en contra de la conversión de la tierra en un modelo extensivo y monoproductivo (con las plantaciones de palma africana), que le abre las puertas a las transnacionales de la tierra y alimentos, a costa de la producción para el autoconsumo o consumo local, creando mayores dependencias, así como contra la expropiación del control del agua.

Estas serían para la CONAIE algunas de las medidas que podrían contribuir a una transformación que mira al futuro. Es en este contexto que se deben interpretar las reacciones de las organizaciones indígenas históricas que muchos perciben como irracionales o exageradas.

La plurinacionalidad, los territorios y la identidad de pueblos originarios son considerados como obstáculos al proyecto modernizador, mientras que para las poblaciones indígenas este proyecto modernizador se implanta como destructor de la identidad y del buen vivir indígena, sin entender la realidad y la perspectiva indígena. La urbanización acelera la disolución socio-cultural de comunidades y pueblos indígenas mientras que se intenta folklorizar y exotizar la cultura y las cosmovisiones con planes de ecoturismo.

\section{REFLEXIÓN FINAL}

Figura 3. Movilización de agosto 2015 en el cantón Saraguro, provincia de Loja. Foto: www:eltiempo.com.ec
La modernidad se fundó en la desconfianza de lo múltiple, se reprimió la diversidad, se intentó homogeneizar, sin tener en cuenta 
las necesidades diferenciadas. Se impulsó un modelo productivo subordinado al modelo capitalista, sin importar qué se produce y cómo se produce. El culto al consumo para engrosar las arcas de unos pocos sin tener en cuenta los residuos que se generan y la gestión de ellos, rompiendo los equilibrios locales, comunales e individuales.

Los pueblos originarios amazónicos, los últimos afectados por la expansión capitalista, han formado parte de las estrategias de inclusión y sometimiento de las políticas indigenistas de sus propios Estados, han sido la materia prima de las políticas de modernización y desarrollo.

La propiedad privada de la tierra asociado con el prestigio y el desarrollo del propietario, frente a quienes sostienen que la propiedad comunal está fundada en la cosmovisión de que los seres humanos no somos propietarios de la tierra sino que vivimos en relación con ella, intenta imponerse a costa del deicidio y genocidio cultural, así como de la pérdida de la biodiversidad, llevándonos a un mundo insostenible.

El grito del Sur que anuncia al mundo el "aquí estamos", "resistimos", "existimos", "somos". Negados por la colonialidad del poder, invisibilizados por los medios de comunicación y por las políticas estatales, reclaman el reconocimiento de su existencia y de su propuesta. Descolonizar las estructuras estatales e instituciones, interculturalizar la pluriculturalidad, la plurinacionalidad, porque el Estado plurinacional es la grieta en la hegemonía liberal del Estado-nación. Mientras exista ese contexto de violencia que es inherente tanto a la modernidad como al capitalismo, la plurinacionalidad es un horizonte de visibilidad para la emancipación.

Sin duda, estos esfuerzos son reflejo y manifestación de la insurgencia política y epistémica; epistémica no sólo por cuestionar, desafiar y enfrentar las estructuras dominantes del Estado, como señala Catherine Walsh, y los intereses de la oligarquía y del mercado, sino también por poner en escena lógicas, racionalidades y conocimientos distintos que hacen pensar el Estado y la sociedad de manera radicalmente distinta (Walsh, 2007).

Los pueblos originarios nos proponen la "minga" o trabajo colectivo, tal como se pronuncia Tanien Ashini, innu Debemos trabajar de forma colectiva porque ahí es donde radica nuestro poder y, además, actuar así resulta ventajoso.

\section{BIBLIOGRAFÍA}

ALBA, S. (2013) “¿Cuánto vale la vida humana?”, recuperado de http://www.rebelion.org/noticia.php?id=166277

BONET, A. J. A. (2009) “La universidad y la globalización alternativa: justicia cognitiva, diversidad epistémica y democracia de saberes" en Nómadas. Revista Crítica de Ciencias Sociales, 22(2), Madrid: Universidad Complutense, pp. 5-28.

DE SOUSA SANTOS, B. (2009) "Más allá del pensamiento abismal: de las líneas globales a una ecología de saberes", En: Olivé, L. et al., Pluralismo epistemológico, La Paz. Bolivia: CLACSO, pp. 31-85.

DUSSEL, E. (1992) "1492. El encubrimiento del Otro. Hacia el origen de "mito de la Modernidad", La Paz, Bolivia: Plural Editores.

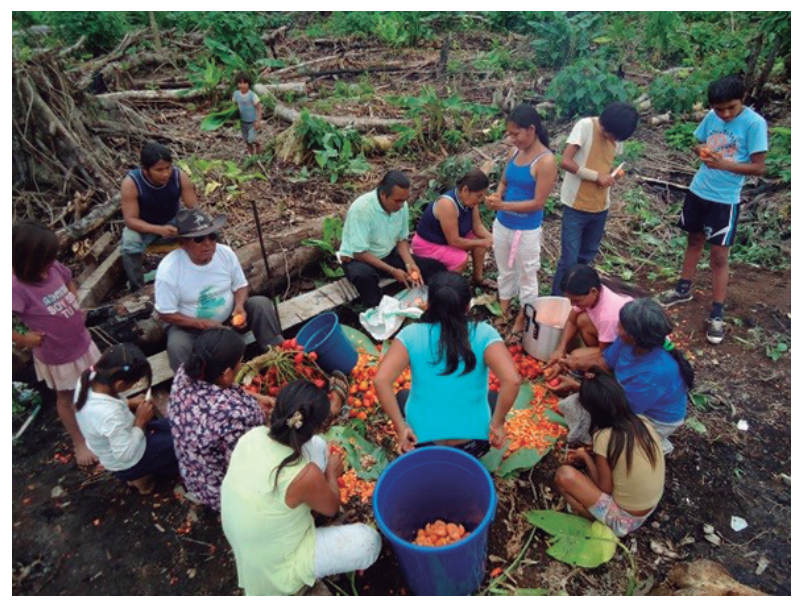

Figura 4. Minga de la comunidad shuar de Taruca, Sucumbíos. Preparación de chicha de chonta. Foto de Tankamash Taant. 
ESCOBAR, A. (2007) "La invención del Tercer Mundo. Construcción y deconstrucción del desarrollo", Caracas: Fundación Editorial el perro y la luna.

FERNÁNDEZ DE LARRINOA, K., (2013), “Del delito cultural”, Zaragoza: Libros Certeza.

HIDALGO, F., HOUTART, F. y LIZARRAGA, P. (Ed.) (2014) “Agriculturas campesinas en Latinoamérica. Propuestas y desafíos”, Quito: Editorial IAEN.

MIGNOLO, W. D. (2003) “Historias locales / diseños globales. Colonialidad, conocimientos subalternos y pensamiento fronterizo", Madrid: Akal.

PRADA, R. (2015) "Territorios indígenas y descolonización", recuperado de http://www.rebelion.org/noticia. php?id=202366

QUIJANO, A. (1992) "Colonialidad y Modernidad / Racionalidad", En: H. Bonilla (Comp.) Los Conquistados: 1492 y la población indígena de las Américas, Quito: FLACSO / Ediciones Libri Mundi, pp. 437-449.

TAVARES, E. (2015) "El mundo indígena y las incomprensiones de la izquierda", recuperado de http://www.rebelion.org/ noticia.php?id=202444

WALSH, C. (2007) "Interculturalidad y colonialidad del poder. Un pensamiento y posicionamiento "otro" desde la diferencia colonial", En: Castro-Gómez, S. y Grosfoguel, R. (comp.), EI giro decolonial: reflexiones para una diversidad epistémica más allá del capitalismo global, Bogotá: Siglo del Hombre.

\section{NOTAS}

1 Gobierno Provincial de Sucumbíos, (2011), Saberes ancestrales de Sucumbíos, Nueva Loja, Ecuador: Ediciones Continente.

2 Término que Alex Mavrocardos utiliza en el contexto de la a veces sistemática privación de derechos de las comunidades por el gobierno o las potencias colonizadoras. Citado en Fernández de Larrinoa, 2013:368.

3 "Territorios indígenas", Raúl Prada los define en términos del uso político, que tienen que ver con las luchas de las naciones y pueblos indígenas por recuperar y reconstituir sus territorios ancestrales en el contexto de la geografía política de los Estados. Dice que se trata de la protección de los pueblos indígenas, no sólo de sus tierras, sino de la defensa de sus culturas, de sus lenguajes, de sus instituciones, de sus normas y procedimientos propios (Prada, 2015).

4 Ubicada en la Amazonía Ecuatoriana, provincia de Pastaza, es uno de los asentamientos kichwas de mayor concentración poblacional y extensión territorial, con alrededor de 1.200 habitantes.

5 Ecuador acepta la competencia de la Corte Interamericana de Derechos Humanos, órgano jurídico de la OEA (Organización de Estados Americanos). De allí que las sentencias de la Corte contienen derechos que en Ecuador tienen rango constitucional.

6 Convenio ratificado el 15 de mayo de 1998 en Ecuador con estatus de Ley Nacional Interna y que sigue vigente.

7 A fecha de 1 de junio de 2013.

8 Colonialidad como la cara oculta de la modernidad, como el otro lado de la modernidad, constitutiva por tanto de la modernidad y no derivativa de ella.
9 Término que utiliza Mignolo para referirse a las lenguas fronterizas.

10 Con extractivismo me refiero a aquellas actividades que remueven grandes volúmenes de recursos naturales que no son procesados (o que lo son limitadamente) cuyo destino, en la mayoría de casos, son mercados externos.

11 http://conaie.org/en/26noticias/198-manifiesto-del-levantamiento-indigena-y-popular-delcampo-y-la-ciudad, recuperado el 28 de agosto de 2015. 